\title{
Analisis Perilaku Keamanan Informasi Pengguna Sosmed Dikalangan Generasi Milenial
}

\author{
John Reimon Batmetan, Morisa F. Lumingkewas, Claudia Tumuyu, Putri P. Ante \\ Prodi Pendidikan Teknologi Informasi dan Komunikasi, Universitas Negeri Manado, Tondano. 95318
}

\begin{abstract}
ABSTRAK
Meningkatnya penggunaan jejaring sosial di indonesia disebabkan oleh semakin lengkapnya fasilitas akses internet yang dilakukan oleh para prodesen penyedia layanan komunikasi. Penelitian ini bertujuan untuk menjelaskan perilaku keamanan informasi pengguna sosmed generasi millenial. Populasi yang digunakan dalam penelitian ini adalah para generasi milenial. Sampel yang digunakan dalam penelitian ini adalah 30 responden generasi millenial. Setelah memperoleh data, selanjutnya dilakukan analisa dengan menggunakan metode skala likert. Hasil penelitian ini menunjukkan bahwa social media memiliki pengaruh signifikan dan positif terhadap keamanan sosmed dikalangan generasi milenial. Oleh karena itu, disarankan kepada para generasi milenial untuk tetap memperhatikan keamanan informasi dalam menggunakan social media.
\end{abstract}

Kata Kunci : sosial media, generasi milenial, usability

\section{PENDAHULUAN}

Perkembangan teknologi informasi semakin mempengaruh hidup manusia. Seiring perkembangannya, masyarakat mulai mengenal adanya internet (Facebook, Instagram, Twiter D1l) yaitu adalah internet yang merupakan wujud perpaduan antara arus komunikasi dengan perkembangan teknologi. Digandrungi masyarakat mengakses salah satu jejaring sosial (facbook). Meningkatnya penggunaan jejaring sosial di indonesia disebabkan oleh semakin lengkapnya fasilitas akses internet yang dilakukan oleh para prodesen penyedia layanan komunikasi. Facebook merupakan media yang paling diminati oleh masyarakat dan paling memeberikan pengaruh terhadap pengetahuan dan motifasi dan sikap perilaku penggunnya. Tidak memandang usia, jenis kelamin, jabatan, dan sebagainya. Dibandingkan dengan media komunikasi lain. Pola penggunaan media sosial oleh generasi milenial dapat dipengaruhi oleh keluarga, lingkungan, dan karakteristik individu generasi milenial. Keluarga merupakan lingkungan pertama dan utama yang memberikan banyak pengaruh terhadap aspek perkembangan sosial anak. Genarasi milenial atau anak yang memiliki latar belakang ekonomi menengah ke atas dapat dengan mudah mengakses jejaring atau media sosial laainnya dengan menggunakan Handphone atau fasilitas internet yang ada di rumah atau warung internet.

Menjalin hubungan erat dan harmonis dengan teman sebaya sangatlah penting pada masa generasi milenia (remaja). Pengaruh teman sebaya pada sikap, pembicaraan, minat, penampilan, dan perilaku lebih besar dari pada pengaruh keluarga. Demikian halnya dengan media sosial ,salah satu contohnya di dapat dari jejaring sosial yang diperolehgenerasi milenia (remaja) melalui teman sebaya dapat mempengaruhi pola penggunaan jejaring sosial. Banyaknya fitur-fitur menarik dalam jejaring sosial/media social membuat mereka cenderung malas dan kecanduan..keadaan tersebut membuat mereka banyak waktu yang terbuang dana aktivitas yang terganggu, seperti sekolah, belajar, makan, tidur, bersosialisasi dengan 
lingkungan sekitar dan membantu orangtua. Karena anak tersebut terlalu lelah dengan kesenangan dalam jejaring/media social tersebut. Selai dampak negatif, media/jejaring social juga memiliki manfaat yang dapat dirasakan oleh penggunanya.

\section{KAJIAN PUSTAKA}

\section{Social Media}

Social media adalah media online yang mendukung adanya hubungan yang intens antar individu menggunakan teknologi berbasis web yang membuat perubahan komunikasi satu arah menjadi dialog interaktif. Teknologi yang membuat penggunanya dengan mudah untuk berinteraksi berbagi pesan dalam bentuk blog, jejaring sosial, wiki/ensiklopedia online, forumforummaya, termasuk virtual worlds. Media sosialberbasispadateknologi internet yang membentuk pola komunikasi dan penyebaran informasi dari satu kebanyak audiens atau pun dari lebih dari itu (Paramitha, 2011:42)

\section{Generasi Millenial}

Generasi millenial adalah generasi yang lahir antara tahun 1980an- 2000. Fase penting yang terjadi saat generasi millenial tumbuh adalah perkembangan teknologi yang memasuki kehidupan sehari-hari. Shiffman \& Kanuk (2007:245). Sedangkan ciri dari generasi ini adalah tingkat pendidikan dan pengetahuan yang lebih baik dari generasi sebelumnya. Terdapat keberagaman dari segi etnik yang lebih baik dari generasi sebelumnya. Generasi millennial sering dinamai echo-boomers atau millennium generation. Nama echo boomers hadir karena mereka yang termasuk dalam generasi ini adalah generasi yang lahir pada masa perang dunia II. Sedangkan dinamai millennium generation karena mereka merasakan perkembangan teknologi dan pergantian tahun millennium.

Karakteristik yang terbentuk pada generasi millenial adalah kecanduan internet, percaya diri dan harga diri tinggi dan lebih terbuka dan bertoleransi terhadap perubahan. Kilber, et al (2014). Penelitian dari Huybers (2011) memperlihatkan gaji, pemberian pengakuan untuk individu, jadwal kerja yang fleksibel, career advancement sebagai faktor yang penting bagi generasi millenial. Kepuasan kerja generasi millennial ditentukan oleh faktor intrinsik seperti kesempatan untuk kepemilikan organisasi, pemberian pelatihan, persepsi atas dukungan supervisor, pekerjaan yang bervariasi dan bermakna, dan keseimbangan antara kehidupan - pekerjaan. Solnet dan Hood (2008).

Fungsi media sosial dapat diketahui melalui sebuah kerangka kerja honeycomb. Menurut Kietzmann, etl (2011) menggambarkan hubungan kerangka kerja honeycomb sebagai penyajian sebuah kerangka kerja yang mendefinisikan media sosial dengan menggunakan tujuh kotak bangunan fungsi yaitu identity, cenversations, sharing, presence, relationships, reputation, dan groups.

1. Identity menggambarkan pengaturan identitas para pengguna dalam sebuah media sosial menyangkut nama, usia, jenis kelamin, profesi, lokasi serta foto.

2. Conversations menggambarkan pengaturan para pengguna berkomunikasi dengan pengguna lainnya dalam media sosial.

3. Sharing menggambarkan pertukaran, pembagian, serta penerimaan konten berupa teks, gambar, atau video yang dilakukan oleh para pengguna.

4. Presence menggambarkan apakah para pengguna dapat mengakses pengguna lainnya.

5. Relationship menggambarkan para pengguna terhubung atau terkait dengan pengguna lainnya.

6. Reputation menggambarkan para pengguna dapat mengidentifikasi orang lain serta dirinya sendiri.

7. Groups menggambarkan para pengguna dapat membentuk komunitas dan 
subkomunitas yang memiliki latar belakang, minat, atau demografi.

\section{METODE PENELITIAN}

Penelitian ini bertujuan untuk mengetahui pengaruh keamanan social media pengguna social media dikalangan generasi milenial. Subject dalam penelitian ini adalah generasi yang lahir pada tahun 1980an 2000 atau yang berumur $15-35$ tahun.

Metode pengumpulan data yang saya lakukan dalam penelitian ini menggunakan kuesioner melalui google form . Pada saat menanggapi pertanyaan, responden menentukan tingkat persetujuan mereka terhadap suatu pernyataan dengan memilih salah satu dari pilihan yang tersedia. Biasanya disediakan lima pilihan skala dengan format seperti: $1=$ Sangat Tidak Setuju, 2 = Tidak Setuju, 3 = Ragu - Ragu, $4=$ Setuju, 5 = Sangat Setuju

Tabel 1. Format pengukuran kuisioner

\begin{tabular}{cccccc}
\hline PK & STS & TS & RR & S & SS \\
\hline 1 & 2 & 3 & 4 & 5 \\
\hline
\end{tabular}

Untuk mendapatkan data yang bersifat ordinal dan diberi skor sebagai berikut :

Keterangan :

PK : Pertanyaan Kuesioner

STS : Sangat Tidak Setuju

TS : Tidak Setuju : Kurang Mudah

RR : Ragu - Ragu

$\mathrm{S}$ : Setuju

SS : Sangat Setuju

\section{HASIL DAN PEMBAHASAN}

Hasil dari penelitian yang berisi 5 pertanyaan yang sudah mewakili 5 aspel usibility dengan menggunakan google forms dan sudah dijawab oleh 30 responden. Setiap pertanyaan dari kuesioner tersebut memiliki tujuan untuk mengukur tingkat usability menurut penerimaan user, yang selanjutnya akan di nilai menggunakan skala Likert. Pertanyaan tersebut telah mewakili kelima aspek Usabillity, diantaranya yaitu learnability, eficiency, memorability, errors, dan satisfaction.

Dari kuesioner yang telah diberikan kepada responden, data dianalisa menggunakan model skala likert.

Tabel 2. Presentase Nilai

\begin{tabular}{ll}
\hline Jawaban & Keterangan \\
\hline $0 \%-19.99 \%$ & Sangat tidak setuju \\
\hline $20 \%-39.99 \%$ & Tidak setuju \\
\hline $40 \%-59.99 \%$ & Ragu-ragu \\
\hline $60 \%-79.99 \%$ & Setuju \\
\hline $80 \%-100 \%$ & Sangat setuju \\
\hline
\end{tabular}

Setelah penyebaran kuesioner yang diberikan kepada 30 responden,maka selanjutnya dilakukan rekap terhadap hasil kuesioner yang diperoleh

Tabel 3 Rekapitulasi Nilai Usibility

\begin{tabular}{|c|l|c|c|}
\hline No & \multicolumn{1}{|c|}{ Pernyataan } & $\begin{array}{l}\text { Presentase } \\
\text { nilai }\end{array}$ & $\begin{array}{c}\text { Ketera } \\
\text { ngan }\end{array}$ \\
\hline 1. & Keamanan Sosial Media & $88 \%$ & SS \\
\hline 2. & $\begin{array}{l}\text { Sosial Media berpengaruh } \\
\text { Positif }\end{array}$ & $84 \%$ & SS \\
\hline 3. & $\begin{array}{l}\text { Sosial media mengeluarkan } \\
\text { banyak biaya }\end{array}$ & $79 \%$ & $\mathrm{~S}$ \\
\hline 4. & $\begin{array}{l}\text { Koneksi internet memiliki } \\
\text { pengaruh positif terhadap } \\
\text { niat penggunaan social } \\
\text { media }\end{array}$ & $81 \%$ & $\mathrm{SS}$ \\
\hline 5. & Kinerja social media & $70 \%$ & $\mathrm{~S}$ \\
\hline
\end{tabular}

Dari analisis yang dilakukan, didapati $88 \%$ responden mengaku bahwa keamanan di media sosial menjadi penting. Sedangkan $84 \%$ responden juga menyatakan media sosial berpengaruh positif dalam aktivitas sehari-hari. Sebanyak 79\% responden menyatakan bahwa mereka mengeluarkan banyak biaya untuk dapat mengakses internet seperti membeli paket data pada smartphone atau modem yang digunakan. Sedangkan $70 \%$ responden mengaku bahwa media sosial berpengaruh terhadap kinerna mereka. 


\section{KESIMPULAN}

Dari analisis data yang telah dilakukan, dapat diambil kesimpulan bahwa social media sangat berpengaruh dikalangan generasi milenial ini. Dan social media juga memiliki fungsi utuk identity, cenversations, sharing, presence, relationships, reputation, dan groups. Bagi generasi milenial ini agar tetap menggunakan social media dengan baik agar bermanfaat bagi kita dan tetap memperhatikan keamanan informasi social media

\section{DAFTAR PUSTAKA}

[1] Antony Mayfield. (E-book) What is Social Media?. London: iCrossing. 2008

[2] R.Rahadi, "Pengukuran Usability Sistem Menggunakan Use Questionnaire Pada Aplikasi Android Interface vol. 6, no. 1, pp. 661-671, 2014.

[3] V.Fuspita, A. Vatresia, and D. Andreswari, "Sistem Pendukung Keputusan Pemilihan Restoran Di Kota Bengkulu Dengan Metode Simple Additive Weighting (Saw) Berbasis Sistem Operasi Android," J. Rekursif, vol. 2, no. 1, pp. 45-52, 2014

[4] Y. Nurhadryani and H. Sukoco, "Pengembangan dan Uji Usability Sistem Informasi Manajemen Pemantauan Kehadiran dan Nilai Ujian Siswa," J. Ilmu Komput. Agri-Informatika, vol. 3, pp. 5866, 2015. 201 2/06/11/pengertianmediasosialperan-serta-fungsiny

[5] J. R. Batmetan Suyoto, J. D. C. L. Suares, "An Empirical Investigation on Customer Behavior to Adopt Mobile Commerce among the Y Generation in Indonesia", Sriwijaya International Conference On Engineering, Science \& Technology [SICEST 2016], 2016

[6] J.R. Batmetan, "Algoritma Ant Colony Optimization (ACO) untuk Pemilihan Jalur Tercepat Evakuasi Bencana Gunung Lokon
Sulawesi Utara", Jurnal Teknologi Informasi-AITI, 2016, vol.13, no.2, pp 3148

[7] L. Madeso, D. R. Kabo, J. R. Batmetan, " Rancang Bangun Sistem Pakar Penentuan Status Gizi Pada Balita Menggunakan Metode Forward Chainning", E-Jurnal UNSRIT, vol.2

[8] J. R. Batmetan, V. R. Palilingan, " Higher Education Students' Behaviour to Adopt Mobile Learning", IOP Conference Series: Materials Science and Engineering, 2018, vol. 306, Issue 1, pp. 012110 (2018)

[9] V. R. Palilingan, J. R. Batmetan, " Incident Management in Academic Information System using ITIL Framework", IOP Conference Series: Materials Science and Engineering, 2018, vol. 306, Issue 1, pp. 012110 (2018)

[10] J. R. Batmetan, A. J. Santoso, Pranowo, " A Multiple-Objective Ant Colony Algorithm for Optimizing Disaster Relief Logistics", Advanced Science Letters, 2017, vol.23, no.3, pp. 2344-2347

[11] M. L. Tompodung, F. Supit, J. R. Batmetan, " Rancang Bangun Aplikasi Sensus Penduduk Berbasis Android", Buletin Sariputra, 2017, vol.7, pp. 57-61

[12] J. R. Batmetan, " Optimasi Strategi Smart Environment Dalam Mitigasi Bencana Menggunakan Multi-Objective Aco (MoAco) Algorithm", Pasca Sarjana Magister Teknik Informatika Universitas Atma Jaya Yogyakarta, 2016 